\title{
THE PREVALENCE AND DETERMINANT FACTORS OF LOW VITAMIN D LEVELS IN PATIENTS WITH PAINFUL DIABETIC NEUROPATHY
}

\author{
RIZALDY TASLIM PINZON ${ }^{1,2 *}$, ANDRYAWAN WAHYU PRADANA ${ }^{1}$, ANGELA $^{1}$ \\ ${ }^{1}$ Department of Neurology, Duta Wacana Christian University, School of Medicine, Yogyakarta, Indonesia. ${ }^{2}$ Department of Neurology, \\ Bethesda Hospital, Yogyakarta, Indonesia. Email: drpinzon17@gmail.com
}

Received: 09 November 2020, Revised and Accepted: 14 January 2020

\section{ABSTRACT}

Objective: Type 2 diabetes mellitus is a major public health problem. Diabetic neuropathy is one of the major diabetes microvascular complications. The previous study suggests that Vitamin D deficiency plays an important role in the development and progression of diabetes and the data in Indonesia are very limited. This study aims to measure the prevalence of Vitamin D deficiency and its determinant factors in patients with painful diabetic neuropathy (PDN).

Methods: This study is a cross-sectional study. The data were obtained from 53 subjects with diabetic peripheral neuropathy. A pre-designed questionnaire was used to collect data on the patient's age, gender, duration of diabetes, comorbidities, any diabetic complications, and current treatment for diabetes mellitus. The Vitamin D levels were measured by a standardized method in the Prodia Research Laboratory.

Results: Study findings showed that from 53 study subjects, most of them were female (79.2\%). The mean age of subjects was $57.83 \pm 8.79$ years. We found a high prevalence of low Vitamin D levels in the Indonesian population as many as $98.11 \%$ and only $1.9 \%$ has sufficiency Vitamin D levels. Gender ( $p=0.028)$, hypertension ( $p=0.027)$, and controlled complications ( $p=0.005)$ were significantly associated with Vitamin D levels.

Conclusion: All patients with PDN in this study had a high prevalence of Vitamin D deficiency. This high prevalence of Vitamin D deficiency also has been reported worldwide. Physician should be aware and continue to treat patients with Vitamin D deficiency.

Keywords: Diabetes mellitus, Vitamin D deficiency, Low Vitamin D levels, Painful diabetic neuropathy.

(C) 2021 The Authors. Published by Innovare Academic Sciences Pvt Ltd. This is an open access article under the CC BY license (http://creativecommons.org/ licenses/by/4.0/) DOI: http://dx.doi.org/10.22159/ajpcr.2021v14i3.40203. Journal homepage: https://innovareacademics.in/journals/index.php/ajpcr

\section{INTRODUCTION}

Type 2 diabetes mellitus (T2DM) is a major public health problem, accounting for significant premature mortality and morbidity [1]. The data from the National Health Survey in Indonesia showed that the prevalence of diabetes increases by $2 \%$ among $>15$-yearold population [2]. Treatment options for type 2 diabetes have dramatically improved, but the rising burden calls for more insights into the prevention and management of the disease [1]. Diabetic neuropathy is one of the major diabetes microvascular complications [3]. The pathogenesis of diabetic peripheral neuropathy is a multifactorial process and multiple hypotheses have been postulated. Previous pre-clinical research concludes that abnormal expression of sodium and calcium channels, metabolic and autoimmune disorders which lead to glial cell activation contributes to the pathogenesis [4].

Vitamin D receptors are present in the $\beta$-cells of the pancreas and Vitamin D has been linked to insulin secretion regulation [5]. The previous review suggests that Vitamin D levels may have an inverse relationship with glycated hemoglobin and low levels of Vitamin D show a correlation to increased incidence of type 2 diabetes [6]. The previous study also suggests that Vitamin D deficiency plays an important role in the development and progression of diabetes, while high plasma Vitamin D is related to lower risk of developing diabetes in high-risk patients. Vitamin D deficiency is involved in central pathogenetic mechanisms of diabetes; it affects insulin sensitivity and $\beta$-cell function [5,6]. The previous epidemiological studies showed that Vitamin D deficiency is common in diabetes. A study conducted in Saudi Arabia reported a prevalence of $59.8 \%$ of Vitamin D deficiency and $38.6 \%$ insufficiency [7]. In India, $32.1 \%$ and $34.6 \%$ of type 2 diabetics had Vitamin D deficiency and insufficiency, respectively [8]. Another recent study in 151 subjects with diabetes found that Vitamin D deficiency and insufficiency were found in $38.4 \%$ and $21.9 \%$ of the participants, respectively [9]. The measurement of Vitamin D is costly in Indonesia. The data about the prevalence of Vitamin D and its determinant factors are very limited. This study can be a basis of adequate management of diabetes and diabetic neuropathy in Indonesia. This study aims to measure the prevalence of Vitamin D deficiency and its determinant factors in patients with painful diabetic neuropathy (PDN).

\section{METHODS}

\section{Study design}

The research was conducted in Bethesda Hospital Yogyakarta, Indonesia. The research was carried out during the period from October 2019 to December 2019. This study is a cross-sectional study in patients with T2DM that suffers from PDN. The data were obtained from 53 study subjects with PDN. The study included all patients above the age of 18 years with symptoms suggestive of peripheral neuropathy.

\section{Ethical committee approval}

Ethical clearance certificate was obtained from Duta Wacana Christian University, Yogyakarta, Indonesia, as the Institutional Ethics Clearance Committee (Ethical Approval: 1125/C.16/FK/2019).

After obtaining approval from the Institutional Ethical Committee, patients were recruited in the study based on the inclusion criteria. Informed consent was obtained and the patients were subjected to history and physical examination. 
Study participants: Inclusion criteria and Exclusion criteria

Patients with neuropathy due to causes other than diabetes and those who refused informed consent were excluded from the study.

\section{Inclusion criteria}

The following criteria were included in the study:

- Male and female

- 18 years old

- Diagnosed as PDN based on diabetic neuropathy examination (DNE) and diabetic neuropathy symptom (DNS) examination

- Low Vitamin D status.

\section{Exclusion criteria}

The following criteria were excluded from the study:

- Subjects with significant renal and liver problem

- Subjects with known hypersensitivity with Vitamin D

- Pregnancy and breastfeeding patients

- Patients that enrolled any clinical trial within a month

\section{Sampling technique and sample size estimation}

The sampling technique was obtained by consecutive sampling method. The sample size was calculated based on an estimate of $80 \%$ prevalence of low Vitamin D in diabetic neuropathy patients, allowing for an error of $10 \%$, from total 350 diabetic patients in 1 year from medical record data, and thereby, a total of 53 patients were recruited.

\section{Data collection}

The diagnosis of diabetic peripheral neuropathy based on systematic measurement by neurologist with DNS and DNE tools. T2DM patients were obtained from the outpatient neurology clinic of Bethesda Hospital Yogyakarta, Indonesia. A pre-designed questionnaire was used to collect data on patient's age, gender, duration since diagnosis of diabetes, other comorbidities, drug history, any diabetic complications, and current treatment for diabetes. The severity of neuropathy was measured with the Toronto Clinical Neuropathy Scoring (TCNS) system. The individual patient's TCNS was documented out of a total of 19 . The severity of neuropathy was classified based on the score as: No neuropathy (0-5), mild neuropathy (6-8), moderate (9-11), and severe diabetic neuropathy (12-19)

The Vitamin D levels were measured by a standardized method in the Prodia Research laboratory. Measurement of 25(OH)D levels was done by enzyme immunoassays for the quantitative measurement of total serum $25(\mathrm{OH}) \mathrm{D}$ levels. The levels $<10 \mathrm{ng} / \mathrm{mL}$ are deficiency, 10-29 ng/mL are in-sufficiency, and 30-100 ng/mL are sufficiency. We also performed a systematic search in PubMed for other similar studies worldwide for data comparison.

\section{Data analysis}

Continuous variables were assessed for normality using KolmogorovSmirnov's test. If the variables were normally distributed, they were expressed as mean \pm standard deviation, otherwise mean rank. Categorical variables were expressed either as percentages or proportions. Comparison of normally distributed continuous variables was done by independent sample t-test, non-normally distributed continuous variables by the Mann-Whitney U-test, and significant variable continuous by multivariate linear regression. Data analysis and validation were carried out by SPSS Statistics version 23. All $\mathrm{p}<0.05$ were considered statistically significant.

\section{RESULTS AND DISCUSSION}

This study was conducted on 53 subjects of PDN with a much higher proportion of 42 females (79.2\%) and 11 males (20.8\%) had statistically significant relationships with Vitamin D levels $(\mathrm{p}=0.028)$. The average age of PDN patients in this study was $57.83 \pm 8.79$ years. The results of this study are almost the same as the previous studies which showed that the number of females $(57.9 \%)$ was significantly greater $(\mathrm{p}=0.001)$ than male $(42.1 \%)$ with an average age of $57.83 \pm 8.79$ [9]. The duration of patients suffering from diabetes is mostly $<10$ years and only a few have poor glycemic control. Based on age, diabetes duration, and differences in clinical neuropathy, females had a greater prevalence of occurrence neuropathy and 50\% increased risk severe neuropathy symptoms than males [10]

The high prevalence of the occurrence of Vitamin D deficiency has been reported worldwide. Vitamin D deficiency plays an important role in the process of the occurrence of non-bone diseases, such as diabetes and cardiovascular disease [11]. The average of Vitamin D levels in this study was $15.57 \pm 6.99 \mathrm{ng} / \mathrm{mL}$. Table 1 shows that the prevalence of low Vitamin D levels in the Indonesian population was $98.11 \%$. Only one study subject has sufficient Vitamin D levels. The proportion of subjects with deficiency is significant $12 / 53$ (22.6\%). Most of the study subjects have insufficient Vitamin D levels as many as $75.5 \%$ and $22.6 \%$ had Vitamin D deficiency. These results are similar to previous studies in Greeks, with $17.5 \%$ having Vitamin D deficiency and 63.3\% with Vitamin D insufficiency [12]. The previous studies on Asians in the UK found $13 \%$ and $70 \%$ of type 2 diabetics had Vitamin D deficiency and insufficiency, respectively [13]. This result is consistent with some previous studies (Table 2).

The results of evaluations of 9773 US adults over the age of 18 carried out by the National Health and Nutrition Examination (NHANES) group study (2003-2006), confirmed a mechanistic relationship between serum Vitamin D levels, glucose homeostasis, and the evolution of diabetes mellitus. The National Health and Nutrition Examination Survey (NHANES) III study (1988 and 1994) demonstrated that there is a strong inverse association between low levels of Vitamin D and the prevalence of diabetes [19].

Table 1: Characteristics and clinical features of the study subjects

\begin{tabular}{|c|c|c|}
\hline Characteristic & Frequency $(n=53)$ & Percentage \\
\hline \multicolumn{3}{|l|}{ Gender } \\
\hline Male & 11 & 20.8 \\
\hline Female & 42 & 79.2 \\
\hline \multicolumn{3}{|l|}{ Age } \\
\hline$<60$ years old & 33 & 62.2 \\
\hline$\geq 60$ years old & 20 & 37.8 \\
\hline \multicolumn{3}{|c|}{ Duration of diabetes (years) } \\
\hline$<10$ & 29 & 54.7 \\
\hline $10-15$ & 12 & 22.6 \\
\hline$>15$ & 12 & 22.6 \\
\hline \multicolumn{3}{|l|}{ Complications } \\
\hline \multicolumn{3}{|l|}{ Controlled } \\
\hline Yes & 35 & 66.0 \\
\hline No & 18 & 34.0 \\
\hline \multicolumn{3}{|l|}{ Comorbidity } \\
\hline \multicolumn{3}{|l|}{ Hypertension } \\
\hline Yes & 26 & 49.1 \\
\hline No & 27 & 50.9 \\
\hline \multicolumn{3}{|l|}{ Cardiovascular } \\
\hline Yes & 13 & 24.5 \\
\hline No & 40 & 75.5 \\
\hline \multicolumn{3}{|l|}{ Medication } \\
\hline \multicolumn{3}{|l|}{ Antidiabetic drug } \\
\hline Yes & 50 & 94.3 \\
\hline No & 3 & 5.7 \\
\hline \multicolumn{3}{|l|}{ Insulin } \\
\hline Yes & 20 & 37.7 \\
\hline No & 33 & 62.3 \\
\hline \multicolumn{3}{|l|}{ Neuropathy Toronto Score } \\
\hline No neuropathy (0-5) & 0 & 0 \\
\hline Mild neuropathy (6-8) & 11 & 20.8 \\
\hline Moderate (9-11) & 19 & 35.8 \\
\hline Severe (12-19) & 23 & 43.4 \\
\hline \multicolumn{3}{|l|}{ Vitamin D levels (ng/mL) } \\
\hline Deficiency $<10$ & 12 & 22.6 \\
\hline Insufficiency 10-29 & 40 & 75.5 \\
\hline Sufficiency 30-100 & 1 & 1.9 \\
\hline
\end{tabular}


Vitamin D is produced in the skin by being exposed to direct sunlight. Vitamin D is an essential fat-soluble precursor steroid in the human body. Cholecalciferol $\left(D_{3}\right)$ and ergocalciferol $\left(D_{2}\right)$ are the most important forms of Vitamin $\mathrm{D}$. The human body cannot produce $\mathrm{D}_{2}$ but it can be digested in fortified foods or supplements [20]. The lower prevalence of Vitamin D deficiency in various populations can be caused due to climate factors. Tropical countries get greater sun exposure and also longer than European countries some Asian and American countries [9]. Multiple factors contribute to this finding, which include sun exposure, atmospheric pollution, the degree of physical activity, clothing, cultural, and dietary habits [21].

Vitamin D deficiency contributes significantly to the pathogenesis of the two types of diabetes by directly acts on insulin producing cells ( $\beta$ cells) in the pancreas to produce more insulin and increasing insulin resistance [22]. In a previous study, there was evidence that Vitamin D plays a role in the process of regulating beta-cell function by influencing insulin secretion, inhibiting beta-cell apoptosis, or by increasing betacell [23]. In this study, the prevalence of low Vitamin D levels mostly occurred in PDN patients suffering from T2DM. T2DM is a disease caused by abnormalities in insulin sensitivity and the process of insulin secretion. This disorder is usually associated with a sedentary lifestyle and higher levels of inflammation cytokines [24]. Based on previous research, it is suggested that Vitamin D can play a role in increasing the function of beta-cells and increasing insulin sensitivity. NHANES study shows an inverse correlation between 25(OH)D and the incidence of T2DM/insulin resistance [25].

Diabetic patients tend to be easily deficient in B vitamins, Vitamin C, Vitamin D, and many micronutrients, such as chromium, zinc, selenium, magnesium, iron, and manganese. A study by Ahmadieh et al. explains that low concentrations of $25(\mathrm{OH}) \mathrm{D}$ are independent risk factors for PDN. Studies conducted in patients with T2DM have been confirmed that Vitamin D deficiency is associated with neuropathy [7]. Nerve growth factor (NGF) is known to have neuronal benefits in cases of diabetic peripheral neuropathy. Previous confirms that Vitamin D3 (tacalcitol) has been shown to increase expression from NGF [26]. In patients with Vitamin D deficiency, there was proven of increased NGF production after correction with Vitamin D supplementation. Therefore, Vitamin D3 may be useful in preventing and treating neurotropic deficits [27].

In this study, the results of the normality test are not significant. Therefore, a Mann-Whitney statistical test was performed, which demonstrated in Table 3 regarding the determinant factor low Vitamin D levels in patients with PDN or to assessing the Vitamin D levels comparison based on the characteristic data. Based on statistical tests, there were no significant differences in the variables of age, duration of diabetes, cardiovascular disease, antidiabetic drugs, and insulin. There were only three variables with significant results: Gender, hypertension, and controlled complications. To confirm that three variables are related as determinant factors that influence Vitamin D levels, we do a multivariate linear regression test.

Based on multivariate linear regression analysis, all the variables had a significant result that presents in Table 4 . These results indicate that there was a relationship between gender, controlled complications, and hypertension with Vitamin D levels.

The previous studies showed that Vitamin D deficiency was associated with significant coronary artery stenosis in a community-based elderly cohort [28]. Another study showed that low Vitamin D levels are associated with an increased risk of various diseases, such as cancer, hypertension, cardiovascular disease, and another metabolic disease [29]. In this study, there was a significant relationship between low levels of Vitamin D and hypertension $(\mathrm{p}=0.027)$. This results similar to the previous study, there were significant results between hypertension and Vitamin D levels $(p=0.003)$ [11]. The current study suggests, there was a relationship between hypertension with Vitamin
Table 2: Prevalence of Vitamin D deficiency reported in the previous studies among diabetic patients

\begin{tabular}{|c|c|c|c|}
\hline Author & Population & $\begin{array}{l}\text { \% } \\
\text { deficiency } \\
\text { Vitamin D }\end{array}$ & $\begin{array}{l}\% \\
\text { insufficiency } \\
\text { Vitamin D }\end{array}$ \\
\hline Palazhy et al., 2016 [8] & Indians & 71.4 & 15 \\
\hline $\begin{array}{l}\text { Kostoglou-Athanassiou } \\
\text { et al., } 2013 \text { [12] }\end{array}$ & Greeks & 17.5 & 63.3 \\
\hline Lee et al., 2012 [14] & Koreans & 89 & 8 \\
\hline Zahrani et al., 2013 [15] & Saudi & 59.8 & 38.6 \\
\hline Bayani et al., 2014 [16] & Iranians & 64.2 & 25 \\
\hline He et al., 2017 [17] & Chinese & 80 & 14.4 \\
\hline Karau et al., 2019 [9] & Kenyans & 38.4 & 21.9 \\
\hline Khan et al., 2019 [18] & Pakistan & 43.2 & 36.5 \\
\hline
\end{tabular}

Table 3: The Vitamin D levels comparison based on the determinant factors

\begin{tabular}{|c|c|c|}
\hline Variables & $\begin{array}{l}\text { Mean rank } \\
\text { Vitamin D levels }\end{array}$ & p-value \\
\hline \multicolumn{3}{|l|}{ Gender } \\
\hline Male & 39.32 & $0.003^{*}$ \\
\hline Female & 23.77 & \\
\hline \multicolumn{3}{|l|}{ Age } \\
\hline$<60$ years old & 25.44 & 0.344 \\
\hline$\geq 60$ years old & 29.58 & \\
\hline \multicolumn{3}{|c|}{ Duration of diabetes (years) } \\
\hline$<10$ & 28.03 & 0.105 \\
\hline $10-15$ & 32.21 & \\
\hline$>15$ & 19.29 & \\
\hline \multicolumn{3}{|c|}{ Controlled complications } \\
\hline Yes & 31.43 & $0.004^{*}$ \\
\hline No & 18.39 & \\
\hline \multicolumn{3}{|l|}{ Hypertension } \\
\hline Yes & 31.67 & $0.030^{*}$ \\
\hline No & 22.50 & \\
\hline \multicolumn{3}{|c|}{ Cardiovascular disease } \\
\hline Yes & 27.73 & 0.844 \\
\hline No & 26.76 & \\
\hline \multicolumn{3}{|l|}{ Antidiabetic drug } \\
\hline Yes & 27.18 & 0.729 \\
\hline No & 24.00 & \\
\hline \multicolumn{3}{|l|}{ Insulin } \\
\hline Yes & 27.43 & 0.876 \\
\hline No & 26.74 & \\
\hline
\end{tabular}

*Significance when $\mathrm{p}<0.05$

Table 4: Multivariate linear regression model for Vitamin D levels comparison based on the significant determinant factors

\begin{tabular}{llll}
\hline Variables & p-value & Standardized $\boldsymbol{\beta}$ & $\begin{array}{l}\mathbf{9 5 . 0 \%} \text { confidence } \\
\text { interval }\end{array}$ \\
\hline $\begin{array}{l}\text { Gender } \\
\begin{array}{l}\text { Controlled } \\
\text { complications }\end{array}\end{array}$ & $0.028^{*}$ & -0.273 & $-8.812--0.537$ \\
Hypertension & $0.027^{*}$ & 0.355 & $1.688-8.695$ \\
\hline
\end{tabular}

*Significance when $\mathrm{p}<0.05$

D levels. Park et al. also found a significant inverse relationship with serum Vitamin D levels and systolic and diastolic blood pressures [30].

The previous study confirms the findings, there was an association between Vitamin D deficiency and hypertension as cardiovascular risk factors. Vitamin $\mathrm{D}_{3}$ and its analogs play a role in inhibiting renin secretion and activity, thus acting as a negative endocrine regulator of the renin-angiotensin system [31]. In addition, Vitamin $\mathrm{D}_{3}$ has a direct effect on blood vessel walls, which will have antiproliferative effects 
on vascular smooth muscle cells. In vitro studies of vascular smooth muscle cells revealed several mechanisms by which $1,25-(\mathrm{OH}) 2 \mathrm{D}_{3}$ might contribute to pathogenesis occurrence of vascular lesions due to dose-dependent Vitamin $\mathrm{D}_{3}$ activating p38 which is activated by mitogen protein kinase and phosphatidylinositol kinase [32].

NHAES previous study confirmed that insulin resistance, renal function, and Vitamin D status of 14,679 patients assessed, and Vitamin D deficiency had been reported associated with a high risk of developing macrovascular and microvascular complications in patients with type 1 as and type 2 diabetes [33]. Relationship between serum 25-OH concentration of Vitamin D on incidence macrovascular (including myocardial infarction and stroke) and microvascular (retinopathy, nephropathy, neuropathy, and amputation) analyzed showed that a difference of $50 \mathrm{nmol} / \mathrm{L}$ in blood concentrations of 25(OH)D was associated with a $23 \%$ change $(p=0.007)$ in risk of macrovascular complications during the study [34].

In this study, we found that most PDN patients have controlled complications. Complications in PDN patients are also significantly associated with Vitamin D levels $(p=0.005)$. This result similar to the past study showed that there is a definite correlation between Vitamin D levels and diabetes and poorly controlled diabetics. Poorly controlled diabetics have further lower values of Vitamin D when compared with patients with good glycemic control. It is known that poorly controlled diabetic patients are more prone to complications, this is because Vitamin D supplementation in diabetics might improve glycemic control and quality of life and can reduce morbidity and mortality [35].

The limitation of this study is, our study cannot show the causal association between glycemic control and Vitamin D levels. It is a hospital-based study and hence the results may not be generalized to the population on a community basis. The authors could not find sufficient subjects with normal Vitamin D status. We also do not compare the Vitamin D levels in patients without neuropathy. Further studies and clinical trials are warranted.

\section{CONCLUSION}

All patients with PDN in this study had a high prevalence of Vitamin D deficiency. This high prevalence of Vitamin D deficiency also has been reported worldwide. Physician should be aware and continue to treat patients with Vitamin D deficiency.

\section{ACKNOWLEDGMENTS}

Not applicable.

\section{CONFLICTS OF INTEREST}

All authors declare no conflicts of interest.

\section{FUNDING}

There was no funding

\section{REFERENCES}

1. Boulton A, Malik R, Arezzo J, Sosenko J. Diabetic somatic neuropathies (technical review). Diabetes Care 2004;27:1458-86

2. Indonesian Ministry of Health. Indonesian Health Profile Survey. Indonesia: Indonesian Ministry of Health; 2017.

3. Dang C, Boulton A. Changing perspectives in diabetic foot ulcer management. Int J Low Extrem Wounds 2003;2:4-12.

4. Tesfaye S, Boulton A, Dyck P, Freeman R, Horowitz M, Kempler P, et al. Diabetic neuropathies: update on definitions, diagnostic criteria, estimation of severity, and treatments. Diabetes Care 2010;33:2285-93.

5. Al-Timimi D, Ali A. Serum $25(\mathrm{OH}) \mathrm{D}$ in diabetes mellitus Type 2: Relation to glycaemic control. J Clin Diagn Res 2013;7:2686-8.

6. Olt S. Relationship between Vitamin D and glycemic control in patients with Type 2 diabetes mellitus. Int J Clin Exp Med 2015;8:19180-3.

7. Ahmadieh H, Azar ST, Lakkis N, Arabi A. Hypovitaminosis d in patients with Type 2 diabetes mellitus: A relation to disease control and complications. ISRN Endocrinol 2013;2013:641098.

8. Palazhy S, Viswanathan V, Muruganathan A. Prevalence of 25-hydroxy Vitamin D deficiency among Type 2 diabetic subjects of South India. Int J Diabetes Dev Ctries 2016;37:1-5.

9. Karau PB, Kirna B, Amayo E, Joshi M, Ngare S, Muriira G. The prevalence of Vitamin D deficiency among patients with Type 2 diabetes seen at a referral hospital in Kenya. Pan Afr Med J 2019;34:38.

10. Abbott CA, Malik RA, Van RE, Kulkarni J, Boulton AJ. Prevalence and characteristics of painful diabetic neuropathy in a large community based diabetic population in the UK. Diabetes Care 2011;34:2220-4.

11. Darraj H, Badedi M, Poore KR, Hummadi A, Khawaji A, Solan Y, et al. Vitamin D deficiency and glycemic control among patients with Type 2 diabetes mellitus in Jazan City, Saudi Arabia. Diabetes Metab Syndr Obes 2019;12:853-62.

12. Kostoglou-Athanassiou I, Athanassiou P, Gkountouvas A, Kaldrymides P. Vitamin D and glycemic control in diabetes mellitus Type 2. Ther Adv Endocrinol Metab 2013;4:122-8.

13. Tahrani A, Ball A, Shepherd L, Rahim A, Jones A, Bates A. The prevalence of Vitamin D abnormalities in South Asians with Type 2 diabetes mellitus in the UK. Int J Clin Pract 2010;64:351-5.

14. Lee J, Oh S, Ha W, Kwon H, Sohn T, Son H, et al. Serum 25-hydroxyvitaminD concentration and arterial stiffness among Type 2 diabetes. Diabetes Res Clin Pract 2012;95:42-7.

15. Al-Zaharani M. The Prevalence of Vitamin D deficiency in Type 2 diabetic patients. Majmaah J Health Sci 2013;1:18-22.

16. Bayani M, Akbari R, Banasaz B, Saeedi F. Status of Vitamin-D indiabeticpatients. Caspian J Int Med 2014;5:40-2.

17. He R, Hu Y, Zeng H, Zhao J, Chai Y, Liu F, et al. Vitamin D deficiency increases the risk of peripheral neuropathy in Chinese patients with Type 2 diabetes. Diabetes Metab Res Rev 2017;33:2820.

18. Khan H, Rajar I, Memon AR, Naeem N. Vitamin D deficiency in patients with diabetic peripheral neuropathy. J Islamabad Med Dent Coll 2019;7:291-4.

19. Scragg R, Sowers M, Bell C. Serum 25-hydroxyvitamin D, diabetes, and ethnicity in the third national health and nutrition examination survey. Diabetes Care 2004;27:2813-8.

20. Shillo P, Selvarajah D, Greig M, Gandhi R, Rao G, Wilkinson ID, et al. Reduced Vitamin D levels in painful diabetic peripheral neuropathy. Diabet Med 2018;36:44-51.

21. Zarooni AA, Marzouqi FI, Darmaki SH, Prinsloo EA, Nagelkerke N. Prevalence of Vitamin D deficiency and associated comorbidities among Abu Dhabi Emirates population. BMC Res Notes 2019;12:503.

22. Joergensen C, Hovind P, Schmedes A, Parving HH, Rossing P. Vitamin $\mathrm{D}$ levels, microvascular complications, and mortality in type diabetes. Diabetes Care 2011;34:1081-5

23. Takiishi T, Gysemans C, Bouillon R, Mathieu C. Vitamin D and diabetes. Endocrinol Metab Clin North Am 2010;39:419-46.

24. Zimmet P, Alberti KG, Shaw J. Global and societal implications of the diabetes epidemic. Nature 2001;414:782-7.

25. Scragg R, Sowers M, Bell C. Serum 25-hydroxyvitamin D, dia-betes, and ethnicity in the Third National Health and Nutrition Examination Survey. Diabetes Care 2004;27:2813-8.

26. Fukuoka M, Sakurai K, Ohta T, Kiyoki M, Katayama I. Tacalcitol, an active Vitamin D3, induces Nerve growth factor production in human epidermal keratinocytes. Skin Pharmacol Appl Skin Physiol 2001; 14:226-33.

27. Poisbeau P, Aouad M, Gazzo G, Lacaud A, Kemme V, Landel V, et al. Cholecalciferol (Vitamin D3) reduces rat neuropathic pain by modulating opioid signaling. Mol Neurobiol 2019;56:7208-21.

28. Lim S, Shin H, Kim MJ, Ahn HY, Kang SM, Yoon JW, et al. Vitamin D inadequacy is associated with significant coronary artery stenosis in a community-based elderly cohort: The Korean Longitudinal study on health and aging. J Clin Endocrinol Metab 2012;97:169-78.

29. Rosen CJ, Adams JS, Bikle DD, Black DM, Demay MB, Manson JE, et al. The nonskeletal effects of Vitamin D: An endocrine society scientific statement. Endocr Rev 2012;33:456-92.

30. Park HY, Lim YH, Kim JH, Bae S, Oh SY, Hong YC. Association of serum 25-hydroxyvitamin D levels with markers for metabolic syndrome in the elderly: A repeated measure analysis. J Korean Med Sci 2012;27:653-60

31. Qiao G, Kong J, Uskokovic M, Li YC. Analogs of $1 \alpha, 25$ dihydroxyvitamin $\mathrm{D}(3)$ as novel inhibitors of rennin biosynthesis. J Steroid Biochem Mol Biol 2005;96:59-66.

32. Rebsamen MC, Sun J, Norman AW, Liao JK. $1 \alpha, 25$-dihydroxyvitamin D3 induces vascular smooth muscle cell migration via activation of phosphatidylinositol 3-kinase. Circ Res 2002;91:17-24. 
33. Chonchol M, Scragg R. 25-Hydroxyvitamin D, insulin resistance, and kidney function in the Third national health and nutrition examination survey. Kidney Int 2007;71:134-9.

34. Herrmann M, Sullivan DR, Veillard AS, McCorquodale T, Straub IR, Scott R, et al. Serum 25-hydroxyvitamin D: A predictor of macrovascular and microvascular complications in patients with Type 2 diabetes. Diabetes Care 2015;38:521-8.

35. Brijesh M, Saurav P, Prevalence of Vitamin D deficiency in Type-2 diabetes mellitus patients and its correlation with glycemic control. Int J Bioassays 2014;3:3313-7. 